\title{
A AMPLITUDE DO CONCEITO DE CORRUPÇÃO: UM CONFRONTO DE TENSÕES ENTRE INTERESSES PÚBLICO E PRIVADO.
}

\author{
Osvaldo Resende Neto ${ }^{1}$ \\ Carlos Pinna De Assis Junior ${ }^{2}$
}

\section{RESUMO}

O Brasil tem sido cenário de uma série de escândalos de corrupção, ocasionada pela confusão entre interesses públicos e privados, em que estes tendem a prevalecer excessivamente. É nesse panorama em que este trabalho suscita uma análise político-jurídica da amplitude do conceito de corrupção, não se restringindo ao modelo convencional. Para tanto, a pesquisa foi construída sobre três temas: 1) a máxima clássica da supremacia do interesse público; 2) críticas à supremacia do interesse público e o perigo do radicalismo oposto; e 3) para além da corrupção quid pro quo: uma nova proposta do papel do interesse público.

Palavras-chave: Corrupção quid pro quo; Corrupção não convencional; Interesse público; Interesse privado; Ponderação de direitos

\section{THE AMPLITUDE OF THE CONCEPT OF CORRUPTION: A CONFRONTATION OF TENSIONS BETWEEN PUBLIC AND PRIVATE INTERESTS.}

\begin{abstract}
Brazil has been the scene of a series of corruption scandals, caused by the confusion between public and private interests, where these tend to prevail excessively. It is in this panorama in wich work raises a political-legal analysis of the breadth of the concept of corruption, not being restricted to the conventional one. Thus, the research was built on three themes: 1) the classic maxim of public interest supremacy; 2) criticism of the supremacy of the public interest and the danger of opposing radicalism; And 3) beyond quid pro quo corruption: a new proposal on the role of public interest.
\end{abstract}

Keywords: Corruption quid pro quo; Unconventional Corruption; Public interest; Private interest; Weighting of rights

\section{INTRODUÇÃO}

Nas últimas décadas, o desencadeamento de uma série de acontecimentos no cenário nacional, cujo tema principal circunscreve em torno da corrupção, tem provocado os mais acalorados debates políticos. As discussões, fortemente impulsionadas pela imprensa e pelas

\footnotetext{
${ }^{1}$ Mestre pelo Programa de Pós-Graduação de Mestrado em Direito Constitucional pela Universidade Federal de Sergipe; Especialista em Segurança Pública pela Universidade Federal de Sergipe; Especialista em Gestão Estratégica em Segurança Pública pelo Instituto de Educação Ibituruna. Delegado de Polícia Civil do Estado de Sergipe; Diretor do Departamento de Narcóticos do Estado de Sergipe.

${ }^{2}$ Mestrando pelo Programa de Pós-Graduação de Mestrado em Direito Constitucional pela Universidade Federal de Sergipe; Especialista em Direito Público; Advogado; Procurador Geral do Município de Aracaju de 2013 à 2016.
} 
redes sociais, estão sendo vivenciadas em todos os níveis e setores do ambiente político e da sociedade civil. Estende-se desde agremiações político-partidárias, em que seus interesses são defendidos aos gritos na tribuna e no silêncio dos bastidores do jogo político do parlamento, até os embates ideológicos da sociedade civil, inclusive com não raros choques entre manifestantes.

A polarização e o acirramento de ânimo de seus defensores são acentuados pela grave crise econômica pela qual o país vem passando, a qual, segundo muitos, é derivada de toda essa conjectura.

É nesse panorama que este trabalho suscita uma análise político-jurídica da necessidade de amplitude do conceito corrupção, sem, contudo, desaguar em uma seara de insegurança jurídica.

Para tanto, a pesquisa foi desenvolvida em três itens, denominados: 1) a máxima clássica da supremacia do interesse público;2) críticas à supremacia do interesse público e o perigo do radicalismo oposto; e 3) para além da corrupção quid pro quo: uma nova proposta do papel do interesse público.

No primeiro capítulo, expõe-se sucintamente a construção teórica da supremacia do interesse público. No segundo, por sua vez, são apresentadas as críticas contemporâneas à referida teoria, todavia sem deixar de se atentar para os perigos do radicalismo oposto, especialmente quando se tem como pano de fundo situações concernentes à corrupção. No terceiro capítulo, é delineada a construção histórica do conceito de corrupção no direito norte americano, em que são discutidas tensões entre o interesse público e direitos individuais.

Finalizados os itens, é apresentada uma breve conclusão perseguindo uma correlação harmoniosa e sequencial dos temas abordados estabelecida por premissas.

No decorrer desta pesquisa serão expostas posições doutrinárias de autores nacionais e estrangeiros que tratam das abordagens emergidas ao longo da leitura, através da pesquisa bibliográfica de obras, tendo a internet como ferramenta auxiliar.

\section{A máxima clássica da supremacia do interesse público}

Ao tratar sobre o interesse público, a primeira imagem que tende a surgir está intimamente relacionada com a própria ideia de coletividade, a qual, por sua vez, é corolário 
do regime democrático, cujos postulados devem permear toda atividade estatal e também a iniciativa privada, ainda que estejam sendo debatidas questões estritamente concernentes à esfera individual. Nesse diapasão, deve pautar todas relações jurídicas: dos particulares entre si, deles com pessoas de direito público e destas entre si (BARROSO, 2015, p. 96).

A título de exemplo, pega-se como referência a exigência constitucional de que a propriedade particular deve atender a sua função social, consoante norma prevista no art. $5^{\circ}$, inciso XXIII, da Carta Magna e na exigência disposta no art. 1.228, § $1^{\circ}$, do Código Civil. Mesmo nesses casos, devem estar contemplados os interesses sociais, os quais traduzem a permanente necessidade de persecução ao bem comum, evidenciando-se uma destinação positiva que deve ser dada à coisa privada" ${ }^{3}$ "No mundo moderno, o direito individual sobre as coisas impõe deveres em proveito da sociedade e até mesmo no interesse de não proprietários" (GOMES, 2004, p. 129).

Cita-se, em se tratando de direito administrativo, que é viciada à finalidade do ato quando o administrador o pratica em descumprimento do interesse público (sentido amplo) ou em desrespeito ao objetivo diverso daquele explícito ou implicitamente previsto em lei ${ }^{4}$. Desse modo, afirma-se que houve desvio de finalidade porque "o fim de interesse público vincula a atuação do agente, impedindo a intenção pessoal" (MEDAUAR, 2013, p. 157). Por conseguinte, o ato administrativo praticado com objetivo diverso do interesse público ou específico em lei é viciado.

O debate que envolve o conteúdo e alcance normativo do interesse público não se encontra adstrito tão somente ao âmbito das relações jurídicas da administração pública. Sua presença é visível em todos os campos do Direito no ordenamento jurídico brasileiro. No entanto, é no Direito Administrativo que as discussões foram mais intensas, suscitando argumentos justificadores para posicionamentos que ora tendem a enaltecer o interesse público através de uma supremacia, ora privilegiam os interesses individuais sob o fundamento da dignidade da pessoa humana. Por esse motivo, passar-se-á à exposição de teses administrativistas sobre o assunto, porém ressalvando, desde logo, que a abrangência que se pretende acerca do interesse público não pode ficar exaurida apenas a um segmento da ciência jurídica.

\footnotetext{
${ }^{3}$ Essa mesma linha de raciocínio consta no enunciado n. 07, aprovado na V Jornada de Direito Civil.

${ }^{4}$ A caracterização do desvio de finalidade pode se dar em seus dois sentidos - amplo e restrito - de modo que se pode concluir que o conceito legal de desvio de finalidade ou de poder, constante no art. $2^{\circ}$, parágrafo único, "e", da Lei no 4.717/1965, está incompleto (DI PIETRO, 2015, p. 288).
} 
Iniciando, explicita-se que o chamado do princípio da supremacia do interesse público sobre o particular no direito positivo brasileiro é dada através dos estudos que o contemplam na categoria de princípio constitucional implícito (SILVA, 2013, p. 14).

Aloca-se como implícito porque sua existência não se encontra expressa no texto constitucional, mas através de interpretações doutrinárias, dentre as quais as construídas dos dispositivos constitucionais art. $5^{\circ}$, XXIV e XXV, art. 170, incisos III, V e VI ${ }^{5}$, que, mesmo não mencionando supremacia ou grau hierárquico do princípio, servem para extração de seu conteúdo implícito (MELLO, 2015, p. 96).

Desde o seu surgimento no direito brasileiro, que remonta à década de sessenta do século pretérito, o princípio da supremacia do interesse público foi amplamente defendido pelo administrativista Celso Antônio Bandeira de Mello, para o qual, ao lado da indisponibilidade do interesse público, é um dos pilares do regime jurídico administrativo. Esse entendimento leva o autor à identificação de duas consequências jurídicas: 1) posição privilegiada conferida ao poder público para a tutela de interesses públicos; e 2) a supremacia manifestada em uma relação de verticalidade entre a administração e os particulares (MELLO, 2015, p. 70).

Assim, eventuais tensões existentes entre o interesse público e privado, segundo seus defensores, aquele normalmente prevalecerá. Quando o interesse público (de toda coletividade) estiver em jogo, prevalecerá sobre o privado (FIGUEIREDO, 2004, p. 67). "Sempre que entrarem em conflito o direito do indivíduo e o interesse da comunidade, há de prevalecer este, uma vez que o objeto primacial da administração é o bem comum" (MEIRELLES, 2008, p. 50).

Celso Antônio Bandeira de Mello (2015, p. 61) aduz também que o interesse público não tem existência autônoma e desvinculada dos interesses individuais, pois é uma forma qualificada destes, ou seja, uma de suas manifestações. Afirma que os interesses individuais se expressam de dois modos distintos. Uma primeira quando representa interesses meramente particulares de cada indivíduo. Uma segunda forma quando é manifestação dos interesses individuais do cidadão como componente da coletividade.

A respeito dessa relação entre interesse público e privado, Jorge Hector Escola (1989, p. 61) assevera que "o interesse público deve ser conceituado como o interesse

\footnotetext{
${ }^{5}$ As normas constitucionais previstas art. $5^{\circ}$, XXIV e XXV, art. 170, incisos III, V e VI, versam sobre desapropriação, requisição, função social da propriedade, defesa do consumidor e meio ambiente, respectivamente.
} 
resultante do conjunto de interesses que os indivíduos pessoalmente têm quando considerados em sua qualidade de membros da sociedade e pelo simples fato de o serem".

A justificativa da existência da supremacia do interesse público para seus defensores reside no fato de que o Estado avoca para si como o grande responsável pela defesa do interesse coletivo, no caso, os interesses públicos primários (MELLO, 2015, p. 24). Tanto é que a supremacia não deverá se impor frente ao particular, caso o interesse a ser tutelado pelo poder público não seja interesse público em sua essência, mas interesse da pessoa jurídica de direito público.

Essa limitação ao princípio da supremacia do interesse público já era traçada no ano de 1960 pelo italiano Renato Alessi (1970, p. 184), o qual distinguiu os interesses públicos primários, cuja satisfação estava a cargo do Estado, dos interesses de uma determinada organização jurídica coletiva, que denominou de interesses secundários.

Seguindo os ensinamentos do Professor italiano de Direito da Universidade de Bolonia, BARROSO (2015, p. 94-95) detalha que o interesse público pode ser primário ou secundário. O primeiro é a razão de ser do Estado e sintetiza-se nos fins - de interesse de toda sociedade - que cabe a ele promover: justiça, segurança e bem-estar social. Para sua defesa, há o Ministério Público e a Defensoria Pública e ações como a popular e a civil pública para tutela de interesses gerais da coletividade.

Já o interesse público secundário reflete os interesses da pessoa jurídica do direito público que seja parte em determinada relação jurídica - União, Estados, Distrito Federal, Municípios e respectivas autarquias e empresas públicas. Em termos gerais, confunde-se com os interesses do erário, em maximizar a arrecadação e minimizar as despesas. São defendidos pela Advocacia Pública.

No tocante aos eventuais conflitos com o interesse particular, Barroso (2015, p. 95 96) assevera que o interesse público secundário jamais possuirá supremacia a priori e abstrata, cabendo ao intérprete proceder a devida ponderação à vista dos elementos normativos e fáticos para o caso concreto ${ }^{6}$. Contudo, diferentemente ocorre nas situações de colisão com o interesse primário, vez que este "há de desfrutar de supremacia em um sistema constitucional e democrático", tendo em vista consubstanciar valores fundamentais.

\footnotetext{
${ }^{6}$ Não que o interesse público secundário seja desimportante, até porque os recursos financeiros para consecução dos interesses primário pelo Estado são obtidos através da defesa dos interesses secundários.
} 
Barroso (2015, p. 96-97) prossegue suscitando a complexidade do debate quando o confronto envolve interesse público primário consubstanciado em uma meta coletiva e o interesse público primário que se realiza mediante a garantia de um direito fundamental. Estes casos são os mais dificultosos e que se vinculam diretamente o cerne deste trabalho.

Nesses casos de colisões, leciona que o intérprete deverá observar dois parâmetros: a dignidade humana e a razão pública (BARROSO, 2015, p. 96-97. A máxima da dignidade da pessoa humana exposta na Constituição de 1988, como um dos fundamentos da República Brasileira, conduziu a doutrina contemporânea defender a necessidade de reconstrução da visão clássica do princípio da supremacia do interesse público de modo a harmonizá-lo com a nova ordem de direitos fundamentais inaugurada (SILVA, 2013, p. 11).

\section{Críticas à supremacia do interesse público e o perigo do radicalismo oposto}

Um dos primeiros a questionarem a superioridade do interesse público, no Brasil, foi Humberto Bergmann Ávila (1998, p. 165), alegando diversos contrapontos, dentre o reconhecimento de que, com a nova ordem constitucional, "o interesse privado e o interesse público estão de tal forma instituídos pela Constituição brasileira que não podem ser separadamente descritos na análise da atividade estatal e de seus fins".

"Da condição de súdito, de mero sujeito subordinado à Administração, o administrado foi elevado ao status de cidadão" (BAPTISTA, 2003, p. 128). Nota-se que a autora menciona o tratamento constitucional dado à cidadania, um dos fundamentos da República Brasileira, como uma das forças propulsoras a alterar o paradigma clássico em debate. A cidadania passa a ser concebida uma dupla dimensão: 1) nas situações de exercício direto ou indireto do poder político; e 2) na obrigação do Estado de possibilitar aos seus cidadãos a concretização de direitos fundamentais que permitam a existência digna (SILVA NETO, 2006, p. 222).

Rebatendo o princípio da supremacia com a justificativa de incompatibilidade com a a ordem constitucional vigente, cite-se Daniel Sarmento (2005, p. 26):

Contudo, de um tempo para cá, vozes autorizadas vêm se levantando na doutrina para contestar a existência do princípio em pauta, ou para dar a ele uma nova formulação, mais compatível com os direitos fundamentais e o estatuto axiológico do Estado Democrático de Direito. 
Outro ponto de embate pela nova doutrina reside na imprecisão e vagueza da expressão interesse público, que interfere inevitavelmente no conteúdo e alcance do respectivo princípio da supremacia (ÁVILA, 1998).

Fábio Medina Osório (2000, p. 73) também critica a supremacia pela vagueza e multivariedade de sentidos que o termo interesse público pode assumir. "O conteúdo e a caracterização dependem de múltiplos fatores, normativos e metanormantivos, que mereciam debate aprofundado".

Além da "absoluta indeterminação do conceito de interesse público", Daniel Sarmento (2005, p. 27) acrescenta a profunda crise no contexto atual em virtude da fragmentação e pluralismo que marcam a sociedade contemporânea, "nas quais se torna por vezes impossível extrair, à moda de Rousseau, uma noção homogênea de bem comum ou de vontade geral".

O autor (SARMENTO, 2005, p. 52) identifica duas perspectivas discrepantes nas teses justificadoras da supremacia do interesse público: o organicismo e o utilitarismo. No organicismo, o interesse público seria algo superior e diferente do somatório dos interesses individuais. "O organicismo é uma teoria que concebe as comunidades políticas como uma espécie de 'todo vivo', composto por indivíduos que nela desempenham papel semelhante a de um órgão dentro do corpo humano".

Já a doutrina utilitarista se baseia no reconhecimento racional de igualdade entre todas as pessoas que integram a sociedade política, de modo que o melhor objetivo a ser perseguido é o que promove o bem-estar, prazer, felicidade ou preferências racionais do maior número de pessoas. É concebida como consequencialista "o juízo sobre um determinado ato porque não depende da sua conformidade com princípios morais anteriores, mas das consequências que ele produzirá sobre os interesses dos membros da sociedade". (SARMENTO, 2005, p. 52).

Daniel Sarmento cita ainda a doutrina individualista, que contrapõe os postulados organicistas e utilitaristas, conferindo uma primazia aos direitos individuais sobre os interesses coletivos. As três teorias não se compatibilizam com a ordem constitucional brasileira, que centra na dignidade da pessoa humana e, consequentemente, na igualdade substancial, na solidariedade, em direitos sociais etc. (SARMENTO, 2005, p. 52).

Não se pretende aqui expor e dissecar minuciosamente a riqueza de todos argumentos que combatem o princípio da supremacia do interesse público, mas apenas constatar que o 
clássico princípio da supremacia vem sendo fortemente criticado, sem, em algumas ou muitas oportunidades, tomar as devidas cautelas necessárias para não se deixar cair no radicalismo oposto.

Não se pode olvidar que o interesse público primário (valendo-se do secundário) vincula-se, antes de tudo, à finalidade maior da gestão pública: a dignidade da pessoa humana. E, como se afirmou, o seu titular é o povo.

O interesse público assumiu uma perspectiva especial e relevante com o advento da Constituição de 1988, uma vez que consagrou a administração honesta e eficiente como um direito fundamental do cidadão, sendo imprescindível para que o poder público promova a existência humana com o mínimo de dignidade. Nessa toada, a própria concretude dos direitos fundamentais pelo Estado traduz em uma dimensão do interesse público.

Ressalta-se que não se pretende reviver o clássico paradigma da supremacia do interesse público. Contudo, não se pode simplesmente relegar o interesse público a um plano inferior com o mero argumento de se opor a outros direitos individuais, alterando, em algumas situações (às vezes, até causídicas), o entendimento outrora firmado sob a alegação de resguardar direitos individuais. De igual modo, é desarrazoado.

Atualmente, muito se debate sobre a inexistência da preponderância do interesse público sobre o privado. No entanto, parece faltar o mesmo fulgor para a análise das consequências a médio e a longo prazo do sacrifício do interesse público quando levado aos excessos. Essa tendência se mantendo, indaga-se aqui se o Estado terá condições (muitas vezes precárias) de manter o mesmo aparato estrutural, financeiro e jurídico indispensáveis para a concretização dos direitos fundamentais de todos outros cidadãos, individual ou coletivamente considerados. Ademais, os custos não se resumem aos financeiros, englobando outros, inclusive comportamentais (BOLESINA; LEAL, 2013, p. 82-83).

Pensa-se na hipótese de disposição dispendiosa para tratamento de saúde de determinado paciente quando existem outras alternativas médico-farmacêuticas medianas. Imagina-se quantos enfermos terão prejuízos em seus tratamentos diante desse quadro. Não é demais pensar que a proliferação dessas situações trará prejuízos na manutenção da parca rede pública de saúde (distribuição de medicamentes, atendimento clínico etc.).

Recorda-se ainda os polêmicos descumprimentos de decisões judiciais e de desrespeito à Lei n. 12.965/2014 (Lei do Marco Civil) por empresas controladoras de redes sociais, a exemplo do aplicativo whatsapp gerido pelo Facebook. Quantas atrocidades 
cometidas por organizações criminosas devem perdurar saqueando os cofres públicos ou instituindo um poder paralelo enquanto se permite seu funcionamento sob o discurso da existência de punições alternativas (até o presente momento ineficazes), quando, na verdade, a tolerância com a ilicitude decorre da satisfação individual de continuar utilizando o serviço, mesmo havendo outros aplicativos com idênticas funções. A satisfação pessoal parece vendar os olhos da conclusão lógica de que se há um meio de comunicação imune à fiscalização, ele também será o principal instrumento de comunicação para cometimento de crimes, notadamente nos delitos mais complexos ou que ultrapassem as divisas e fronteiras. Fazendo um paralelo com uma situação similar, caso determinada emissora de rede de televisão passe a descumprir a legislação nacional de prestação de serviço público e a normatização da Agência Nacional de Telecomunicação, ela deve permanecer transmitindo determinada novela tão somente porque é a de maior audiência nacional?

Trazendo o debate para a esfera criminal, toma-se como exemplo as ações criminais cujo objeto são infrações relacionadas ao colarinho branco ou à corrupção. A experiência brasileira demonstra que é comum, em especial, nos casos em que o rombo ao erário foi maior, não prosperarem em razão de garantias processuais, algumas das quais exageradas e descabidas. Condenações que se desvanecem no tempo pela prescrição, abuso no uso de recursos com intuito protelatório, amplitude do instituto do habeas corpus, foro por prerrogativa de função em crimes comuns etc. (MATTOS, 2015, p. 16-17).

Esses casos transparecem um certo e egoístico exagero na amplitude dos interesses particulares em detrimento do interesse público. Como se este fosse uma antítese ou negação daquele. Esse pensamento chega a remontar os costumes políticos e administrativos brasileiro da gestão da res publica por agentes estatais como se privada fosse, causando uma verdadeira confusão entre o público e privado (SARMENTO, 2005, p. 28).

Explicita-se, novamente, que não se quer retomar a supremacia do interesse público. Não se trata disso. Entrementes, observa-se, com certo cuidado, que sua mitigação exagerada e paulatina poderá acarretar, em um futuro, em consequências desastrosas para esses mesmos direitos individuais usados como oposição. Os interesses públicos e privados não se excluem mutuamente. Ao contrário, complementam-se.

Nesse ponto, preciosas são as palavras de Daniel Sarmento (2005, p. 28):

Porém, no trato do tema é recomendada redobrada cautela. Se, de um lado, a subordinação dos direitos individuais ao interesse coletivo pode ser a ante-sala para 
totalitarismos de variados matizes, de outro, a desvalorização total dos interesses públicos diante dos particulares pode conduzir à anarquia e ao caos geral, inviabilizando qualquer possibilidade de regulação coativa da vida humana em comum.

Delineada as discussões jurídicas nos choques ponderativos que circulam em torno dos interesses público e privado, passar-se-á a debater a importância desse jogo de tensões na reformulação daquilo que deva ser concebido como ilícito relacionado à corrupção, notadamente nos casos que vão além do modelo tradicional.

\section{Para além da corrupção quid pro quo: uma nova proposta do papel do interesse público}

As tensões entre os interesses público e privado são muito bem exploradas pela professora e ativista norte americana Zephyr Teachout, em sua obra Corruption in America (2014), quando traça uma análise da corrupção na história do constitucionalismo dos Estados Unidos, desde a época dos fundadores até os dias atuais.

Explicita-se que, embora explore o princípio à luz da história do constitucionalismo norte americano, perceber-se que suas bases servem para toda forma republicana de governo, especialmente a adotada pelo Brasil.

Teachout (2014, cap. 1, p. 1) inicia sua abordagem falando sobre a compreensão do que diz respeito ao gesto de presentear. Não obstante possa transparecer algo banal e de menor relevância, a Professora suscita um tema bastante complexo e intricado, envolvendo questões morais, políticas e jurídicas, que está relacionado à ineficácia das normas jurídicas de preservação da administração proba, conforme adiante se demonstrará.

A autora assevera que o presente pode ser um brinde. Da mesma forma, um suborno pode ser um presente. Se um presente é considerado corrupto ou simplesmente generoso depende inteiramente da nossa estrutura cultural ou política (TEACHOUT, 2014, cap. 1, p. 1).

Os presentes são muitas vezes parte do que é melhor na sociedade: eles são uma forma de mostrar as outras pessoas que elas são vistas e valorizadas, talvez até amadas e uma forma de proporcionar recompensas de uma forma não-transacional. Eles levam à amizade e ao calor de uma maneira que nenhum negócio explícito pode, mas o mesmo gesto de presentear, pode desempenhar um papel potencialmente perigoso tanto na prática judicial e democrática. Eles podem criar obrigações para com as partes que moldam o julgamento e os 
resultados dos agentes públicos. Parte do projeto de um sistema político é separar os gestos positivos dos negativos, isto é, definir quais comportamentos devem ser categorizados como corruptos (TEACHOUT, 2014, cap. 1, p. 1-2).

Esse duplo aspecto do gesto presentear mencionado por Zephy Teachout (2014, introdução, p. 1) vem inicialmente à baila quando o então embaixador americano Benjamin Franklin deixa Paris, no ano 1785, após vários anos representando os interesses americanos na França. Em sua despedida, o rei absolutista francês Luís XVI lhe presenteou com um autorretrato cercado por quatrocentos e oito diamantes, colocados em duas fileiras em volta da imagem do rei, guardado em um estojo dourado do tipo caixa de rapé. A caixa de rapé e o retrato valiam até cinco vezes o valor de outros presentes dados a diplomatas e eram superiores a todo patrimônio que o embaixador havia juntado em sua vida.

$\mathrm{Na}$ Europa, os presentes eram socialmente exigidos na partida de um diplomata. Um presente valioso representava o grande favor de um regente e um trabalho bem realizado, mas nos Estados Unidos da época, significava perigo. Um presente tão luxuoso era percebido como tendo o potencial de corromper homens como Franklin (TEACHOUT, 2014, introdução, p. 2).

Em outras palavras, o presente tinha significação positiva de conexão e graciosidade entre o estado anfitrião e o representado pelo embaixador. No entanto, nos Estados Unidos possuía significação negativa de dependência. A caixa de rapé representava a amizade ou a corrupção, o respeito ou o suborno do velho mundo, consoante a perspectiva tomada. Para os americanos era um símbolo de sedução, dependência, luxo e uma confusão europeia sobre a relação apropriada entre política, poder, intimidade e amizade (TEACHOUT, 2014, introdução, p. 2).

A origem da carga negativa da perspectiva americana tem origem na fase colonial e também se fez presente nos primeiros séculos após a formação do Estado. Explicita-se que, durante e após a guerra pela independência norte americana, os fundadores foram motivados pelo medo de serem corrompidos por potências estrangeiras e de adotar hábitos corruptos do Velho Mundo (TEACHOUT, 2014, cap. 1, p. 1-2).

Os americanos começaram sua experiência, logo após a Independência, comprometidos em expandir o escopo das ações que foram chamadas de corruptas para abranger atividades tratadas como não corruptas nas culturas britânica e francesa. Decepcionados com a Grã-Bretanha e a Europa, os americanos sentiram a necessidade de 
constituir uma sociedade política com virtudes cívicas e um profundo compromisso com a capacidade representativa. Não queriam incidir nos mesmos erros dos europeus (TEACHOUT, 2014, introdução, p. 2).

Desse modo, criaram um arcabouço jurídico normativo para repressão à corrupção, onde alguns comportamentos normais na Europa eram concebidos como comportamentos corruptos na América. Os americanos não só criaram um novo país, mas constituíram um sistema político de prevenção a certas práticas danosas (TEACHOUT, 2014, introdução, p. 2).

Benjamin Franklin e a administração pública da época acreditavam que se a moralidade daqueles no poder não for estimulada e preservada, não será possível construir um governo democrático representativo. Quando trataram da temática que envolve a corrupção, os fundadores focaram na orientação moral dos cidadãos e dos representantes, como os elementos fundamentais do Estado Republicano. Outras tradições políticas se concentram nos problemas mais materiais de estabilidade, anarquia, desigualdade ou violência. $\mathrm{O}$ americano deu preponderância às virtudes do amor para o público e os perigos do egoísmo desenfreado. Este compromisso com uma visão ampla da corrupção permaneceu praticamente o mesmo nos tribunais para durante os primeiros duzentos anos dos Estados Unidos (TEACHOUT, 2014, introdução, p. 2).

Em contraposição à concepção dos fundadores, diga-se que também há uma visão restritiva do seu significado, onde a corrupção é reduzida às modernas leis americanas de suborno e extorsão criminal, contemplando situações bem específicas e explícitas, a exemplo de acordos espúrios entre agentes públicos e empreiteiros ou até mesmo hipóteses em que cidadãos comuns aceitam dinheiro para mudar seus votos (TEACHOUT, 2014, introdução, p. 3). Nessa visão restrita, a corrupção é concebida como convencional ou quid pro quo (YINGLING, 2013, p. 10).

No entanto, a corrupção desempenha um papel social e político maior, mais amplo. Retomando à situação fática inicial, vislumbra-se que o incidente do quadro com diamantes e da caixa de rapé demonstrou que a tentação e influência também podem funcionar indiretamente. Desse modo, a corrupção não se restringe a situações convencionais - quid pro quo, como às vezes é chamada (TEACHOUT, 2014, introdução, p. 3).

A expressão quid pro quo tem origem latina, indicando "isso para isso". Seu uso histórico normalmente está no âmbito dos contratos, onde se refere à ideia de um intercâmbio 
relativamente igual entre as partes. $\mathrm{Na}$ ausência de relativa igualdade - quid pro quo - um tribunal poderia invalidar o negócio jurídico (TEACHOUT, 2014, cap. 13, p. 7).

Foi casualmente e coloquialmente usado em relação à corrupção desde o século XIX, pelo menos, onde o quid pro quo se relacionava aos valores recebidos por eleitores em troca de votos ou por agentes públicos em casos explícitos de subornados. Nessas situações, quid pro quo representava um tipo de troca ilícita explícita e específica (TEACHOUT, 2014, introdução, p. 7).

O quid pro quo traduz a solicitação ou oferta clara de algo específico em troca de alguma ação governamental específica. O uso de quid pro quo como um termo legal limitador da corrupção não apareceu na história dos Estados Unidos até os anos 1970, tendo em vista que, desde os fundadores, no século XVIII, a concepção sobre o que entendiam como corrupção ia além da corrupção quid por quo, estando relacionada à moralidade e virtude cívica, de modo que comportamentos nocivos eram desestimulados por normas estruturantes ou profiláticas (TEACHOUT, 2014, introdução, p. 7).

Nota-se que a normatização do recém estado americano refletia a preferência dos fundadores por um certo tipo de norma anticorrupção. Essas normas - estruturais ou profiláticas - abrangem atividades aparentemente inocentes, em contraste as normais penais que exigem prova sobre o dolo para condenação (TEACHOUT, 2014, introdução, p. 3).

Assim, os fundadores trabalhavam com incentivos antes do fato, ao invés de tentar uma condenação após a consumação do ilícito. A legislação então vigente foi construída para o combate à corrupção através de normas estruturais. A título de exemplo, observa-se a exigência constitucional americana de residência eleitoral para concorrerem a vagas do parlamento. Longe da perfeição, trata-se de norma valiosa, pois protege a democracia de aventureiros (TEACHOUT, 2014, Introdução, p. 3).

A nomenclatura corrupção tem uma longa tradição de desempenhar um papel importante na transformação política da nação. As acusações de corrupção e suas variantes foram uma força essencial na criação da Constituição Americana e parte de quase todos os debates sobre a estrutura governamental (TEACHOUT, 2014, introdução, p. 3).

Nos primeiros cem anos da República Americana, o problema da corrupção levou a decisões-chave sobre como estruturar o governo e os negócios e como restringir os legisladores interessados. As acusações de corrupção em todo o sistema possibilitaram a criação do estatuto antitruste de 1880 (TEACHOUT, 2014, introdução, p. 3). 
Atualmente, a amplitude da noção sobre corrupção está agora no centro da disputa legal mais importante na democracia norte americana, que ameaça desvendar o que os fundadores construíram. Esta disputa tem suas raízes no caso Buckley v. Valeo, do ano de 1976, onde a Corte derrubou a legislação que limitava gastos em campanhas políticas. Embora o Tribunal tenha reconhecido que havia uma razão legítima para a pretensão do público em combater à corrupção, decidiu no sentido de que as disposições que limitavam os gastos não têm relação com a corrupção. Consequentemente, não definiu a corrupção nem o restringiu completamente às transações específicas e explícitas (corrupção quid pro quo), como aconteceu, posteriormente, todavia criou uma estrutura jurisprudencial prejudicial aos interesses cívicos e moralidade, afetando as normas estruturais e profiláticas de combate à corrupção, sob o fundamento do direito de liberdade de expressão consagrado na Primeira Emenda da Constituição Americana (TEACHOUT, 2014, cap. 4, p. 3).

A mudança iniciada com a leitura do caso Buckley, em 2006, possibilitou que a entidade conservadora americana Citizens United ingressasse judicialmente defendendo a ausência de limites para doações eleitorais, oportunidade em que a Suprema Corte proferiu uma decisão que estabeleceu uma mudança de paradigma sobre a corrupção na história política americana. Foi permitido que indivíduos e corporações tivessem o direito de gastar tanto dinheiro como quisessem, independentemente de pretenderem influenciar nas eleições e em questões políticas (TEACHOUT, 2014, cap. 4, p. 4).

O cerne do decidido no caso Citizens United foi uma afirmação sobre a natureza da corrupção e seu papel histórico no direito americano. Limitou a corrupção tão somente às situações quid pro quo. Obviamente, a utilização da expressão quid pro quo não foi no sentido literal de contrato entre particulares, como tradicionalmente significava, mas uma compreensão de que para a configuração do ilícito era imprescindível uma troca explícita de algo de valor para um ato legislativo ou executivo específico e identificável. Segundo a Corte, "os gastos independentes, incluindo aqueles feitos por corporações, não dão origem à corrupção ou à aparência de corrupção", bem como que "o fato de que os doadores possam ter influência sobre ou acesso a parlamentares eleitos não conduz que esses agentes públicos são corruptos. Em 2014, a decisão do juiz Roberts em McCutcheon v. FEC consolidou este 
entendimento, afirmando que a única corrupção constitucionalmente cognoscível é a quid pro quo (TEACHOUT, 2014, cap. 4, p. 5) ${ }^{7}$.

Esta nova ordem legal trata a corrupção de forma ligeira e limitada, restringindo o alcance do que é considerado corrupção a negócios explícitos e específicos. Assim, reclassifica a busca de influência como comportamento político normal e desejável, esmagando o conteúdo moral do termo corrupção em uma história no mundo povoado por atores interessados (TEACHOUT, 2014, cap. 4, p. 5).

Sobre os efeitos negativos da modalidade de corrupção não convencional, Amilcar Araújo Carneiro Júnior (2015, p. 11) afirmou que são mais danosos e de difícil comprovação:

\begin{abstract}
Parece ser a forma mais poderosa de corrupção, pois a sua invisibilidade a torna muito mais difícil de ser visualizada e, portanto, de ser investigada e provada. $\mathrm{O}$ exemplo mais contundente, comum em vários países democráticos é o problema associado com incentivos eleitorais, financiamentos privados de campanhas, considerações legais, ou até mesmo o incentivo independente, nomeadamente chamado de "caixa II, esta ilegal, mas de difícil comprovação. Tais financiamentos legais ou ilegais permitem projetar qual será a conduta a ser tomada pelo agente público.
\end{abstract}

A decisão proferia no caso Citizens United foi péssima para o sistema político e exibia uma compreensão ainda pior da história. A visão tradicional difundida pelos fundadores era para criação de estruturas preventivas no poder público que contivessem as tentações que levam ao egoísmo exagerado. Certamente esse pensamento não negava a existência de interesses particulares, porém ao invés de endossá-la cegamente, a abordagem tradicional americana torna o trabalho do governo de temperar o egocentrismo exacerbado na esfera pública (TEACHOUT, 2014, cap. 1, p. 5).

Assim como a liberdade ou a igualdade, a corrupção é um conceito importante para a República e com limites pouco claros. Refere-se a interesses privados excessivos na esfera pública. Um ato é corrupto quando os interesses privados triunfam sobre os públicos no

\footnotetext{
${ }^{7}$ Nesses dois recentes casos - Citizens United e McCutcheon v. FEC -, a Suprema Corte Americana, através dos juízes Anthony Kennedy e John Roberts, decidiu no sentido de que as contribuições de campanhas políticas uma forma de presentear - dadas com a intenção de influenciar o governo não constituem comportamentos de corrupção. Segundo os juízes, a corrupção exige mais do que a intenção por parte do doador de presentes. Requer algo como um acordo explícito entre o doador e o candidato. Quando a Suprema Corte assim se posicionou, os juízes alegaram seguir precedente. Nos primeiros dias da república, os fundadores americanos tomaram a abordagem oposta. Eles desenharam um grande círculo em torno de comportamento que eles inseriram na seara da corrupção, considerando-os como ameaças ao sistema político, mesmo quando tal tratamento interferisse negativamente em negociações internacionais e não fosse acompanhado por um acordo explícito (TEACHOUT, 2014, cap. 1, p. 1-2).
} 
exercício do poder público. Uma pessoa é corrupta quando usa o poder público para seus próprios fins, desconsiderando os outros (TEACHOUT, 2014, cap. 1, p. 5).

Durante a maior parte da história americana, os tribunais permaneceram comprometidos com uma visão ampla e tradicional da corrupção. Contudo, a partir do final da década de 1970, tudo começou a mudar em torno desta questão. A Suprema Corte, junto com um crescente subconjunto de estudiosos, começou a confundir o conceito de corrupção e jogar fora muitas das regras profiláticas que foram usadas para se proteger contra ela (TEACHOUT, 2014, cap. 1, p. 5).

Essa rejeição levou a um estouro do envolvimento da indústria privada em eleições políticas e a um rápido declínio da ética cívica no Congresso e no Legislativo Estadual. As antigas ideias sobre a virtude foram jogadas fora como sentimental, mas os antigos problemas de corrupção e governo persistiram (TEACHOUT, 2014, cap. 1, p. 5).

A era contemporânea está repleta de gestos cordiais e presentes incrustados de diamantes, embora sejam menos prováveis de vir do rei da França. Atualmente, eles vêm de executivos de indústrias altamente concentradas e monopolistas que, como o rei da França em 1785, têm um interesse intenso e pessoal nas escolhas políticas dos poderes legislativos e um desprezo casual pelo processo cívico (TEACHOUT, 2014, cap. 1, p. 6).

Um exemplo notável dos efeitos negativos da corrupção não convencional, que aconteceu recentemente nos Estados Unidos, esteve relacionado à aferição dos padrões nutricionais do governo federal para almoços escolares.

De acordo com os membros da comunidade nutricionista, a obesidade infantil é um problema significativo nos Estados Unidos. De fato, o Departamento de Saúde e Serviços Humanos dos Estados Unidos descobriu que a obesidade infantil triplicou nas últimas três décadas. De conseguinte, vislumbrou-se uma questão de saúde pública, ou seja, de uma das facetas do interesse público. Assim, esperava-se que em atendimento aos interesses públicos o governo americano promoveria almoços escolares mais saudáveis ${ }^{8}$.

\footnotetext{
${ }^{8}$ Em reportagem do site g1, no dia 27 de abril de 2016, noticiou-se que as altas taxas de obesidade em crianças e adolescentes americanos, um fenômeno que começou há cerca de trinta anos e se aprofundou de forma alarmante desde então, persiste sem qualquer sinal de recuo, revelado em um estudo da Universidade de Duke, na Carolina do Norte. Para fazer este estudo, publicado na revista Obesity, os autores analisaram dados de uma pesquisa nacional sobre saúde e nutrição, que abrange várias décadas. O estudo constata que no período 2013-2014, 33,4\% dos jovens de 2 a 19 anos tinham sobrepeso, dos quais $17,4 \%$ eram obesos. Estes percentuais não diferem estatisticamente dos registrados no período anterior, de 2011 a 2012, e mostram que em todas as categorias de sobrepeso e obesidade as cifras mantiveram sua tendência à alta entre 1999 e 2014, constatam os pesquisadores (PRESSE, 20116).
} 
No entanto, em novembro de 2011, o Congresso Americano aprovou um projeto de lei de gastos que rejeitou a proposta do Departamento de Agricultura dos Estados Unidos de exigir uma meia xícara de pasta de tomate para que qualquer alimento seja classificado como vegetal. A proposta do Departamento de Agricultura foi baseada em recomendações do Instituto de Medicina, o braço da saúde da Academia Nacional de Ciências. Ao invés de acompanhar as recomendações do Instituto de Medicina, o Congresso votou para permitir que apenas duas colheres de sopa de tomate para contar como uma porção de legumes, que tem o efeito de classificar uma fatia de pizza como um vegetal (YINGLING, 2013, p. 288).

A essa questão, indaga-se o motivo do Congresso tomar essa atitude se a obesidade infantil era um problema de saúde pública. A resposta é evidente quando se reconhece que os lobistas corporativos, incluindo muitos da indústria de alimentos congelados, que gastaram US\$ 5,6 milhões influenciando os membros do Congresso para relaxar os padrões do almoço escolar. Este é um claro exemplo de agentes públicos eleitos colocando primeira e excessivamente interesses privados em detrimento do interesse público (YINGLING, 2013, p. 288-289).

Ainda em se tratando de saúde pública, a Professora Maria Victoria de Mesquita Benevides (1991, p. 101) exemplifica o poderoso lobby realizado no Parlamento francês pelos viticultores. Na França, há prejuízo para a elaboração de uma política séria contra o alcoolismo, o qual é considerado um problema nacional que afeta, inclusive, adolescentes e crianças. A autora destaca que o lobby mencionado tem capacidade de comprometer efetivamente as chances de reeleição de políticos.

A corrupção não convencional permite a constituição de uma relação de dependência dos candidatos a vagas no Parlamento e Executivo de indivíduos ricos e grandes empresas em razão das contribuições de campanha. O impulso para resistir a esses presentes tentadores é profundamente americano, sendo necessário o caminho de volta às origens da Constituição Americana, época dos fundadores (TEACHOUT, 2014, introdução, p. 6).

No tocante à essa relação de dependência entre o corruptor e o corrupto, seja a convencional (quid pro quo), seja a não convencional, diga-se que tende a ser um caminho pernicioso para o interesse público. A linguagem da dependência e da corrupção são tão interligadas que, em alguns casos, a corrupção e a independência poderiam soar como opostos. Os teóricos contemporâneos, em muitas oportunidades, usam as expressões 
"corrupção" e "dependência" no mesmo contexto, indicando que a corrupção vem se origina como resultado natural da relação de dependência (TEACHOUT, 2015, cap. 2, p. 11).

A Declaração de Independência Americana foi, em parte, uma declaração de libertação da corrupção. Independência é a ausência de uma relação de poder, que simbolizava a rejeição desse tipo de relacionamento. Dependência, por sua vez, poderia se referir a uma espécie de dependência estrutural (onde uma pessoa é realmente dependente dos outros financeiramente e, portanto, deve atender aos interesses daquela) ou uma dependência psicológica (onde o caráter de uma pessoa é corrompido pelas influências de outro para pensar e agir de forma diferente). A dependência financeira pode conduzir à dependência psicológica. Em cada caso, embora em graus variados, a figura dependente mudaria suas ações para alinhar-se com os desejos particulares da pessoa que tinha poder sobre ele (TEACHOUT, 2015, cap. 2, p. 12-13).

Nessa conjectura, assevera-se que a dependência, por si só, não define a corrupção, mas faz parte do conjunto de relações estruturais que levam à corrupção. Um dos objetivos claros da Convenção Constitucional era a liberdade de uma cultura política onde a dependência era o modo primário de avanço. O trabalho da arquitetura política era desencorajar dependências e tentações que poderiam levar à corrupção (TEACHOUT, 2015, cap. 2, p. 12-13).

Na moderna legislação americana de suborno e extorsão, poder-se-ia supor que esses diplomas normativos são ferramentas apropriadas e suficientes para combater efetivamente a corrupção. Entrementes, eles são problemáticos. Se um estatuto de suborno é estreitamente elaborado (ou interpretado), abrange apenas intercâmbios descarados e não sofisticados, não resolvendo realmente problemas surgidos com o emprego de grandes somas de dinheiro para influenciar na política, prejudicando o regime democrático (TEACHOUT, 2014, Introdução, p. 6).

Uma lei penal punirá apenas políticos desajeitados como William Jefferson, que escondeu seus rolos de dinheiro em um freezer ${ }^{9}$. Por sua vez, normas estruturantes ou

\footnotetext{
${ }^{9}$ Em matéria jornalística publicada no Whashingtonpost, no dia 13 de novembro de 2009, noticiou-se que o exdeputado William J. Jefferson foi condenado a 13 anos de prisão, no ano de 2009, por ter aceitado centenas de milhares de dólares em subornos. Foi a maior condenação a tempo de prisão em desfavor de um congressista condenado por acusações de corrupção. A sentença para o democrata de Lousiana ficou muito aquém dos 27 a 33 anos sugeridos sob as diretrizes federais de condenação, uma recomendação aprovada pelos promotores. Mas ele ultrapassou o recorde anterior de corrupção no Congresso: a pena de oito anos e quatro meses de prisão que o ex-congressista Randall "Duke" Cunningham (R-Calif.), no ano de 2006, por aceitar subornos. O caso de
} 
profiláticas, que a Teachout (2014, Introdução, p. 6) chama de leis de intenções corruptas, podem ser mais amplamente interpretadas, visto que as exigências dogmáticas da norma penal dificultam demasiadamente a caracterização do ilícito, deixando de abranger uma série de comportamentos danosos ao sistema político.

Uma lei penal que é concebida como "Guerra contra a Corrupção" é, sem dúvida, como as guerras contra as drogas ou o terrorismo - quase impossível de se ter sucesso. A corrupção é muito melhor lutada através da mudança de estruturas básicas de incentivo. Isso pode parecer intuitivo para qualquer pessoa envolvida na política, mas a maioria da atual Suprema Corte preferiu abertamente a restrição do conceito de ilícito apenas a situações quid pro quo (TEACHOUT, 2014, Introdução, p. 5).

Zephyr Teachout (2014, cap. 1, p. 7) ainda indaga se Benjamin Franklin havia sido efetivamente corrompido pela França por ter recebido o presente do monarca. A história não fornece uma resposta, mas anuncia uma atitude em relação à corrupção e uma maneira de refletir sobre ela. A cláusula constitucional era fundamental porque expressava uma nova visão da maneira apropriada de ser um representante público de um país no estrangeiro.

De conseguinte, é imprescindível uma compreensão mais profunda e minuciosa das complexas formas e ocasiões em que as moralidades privadas e públicas se cruzam, bem como uma maior atenção e respeito pelos perigos políticos que decorrem da ausência de limites para os interesses particulares em questões de interesse público. Essas mudanças propostas, de retorno à concepção tradicional, possibilitarão o apoio judicial para regras claras que impeçam a iniciativa privada e os agentes públicos de sucumbirem às tentações. (TEACHOUT, 2014, introdução, p. 8).

\section{CONCLUSÃO}

O Brasil tem sido cenário nos últimos anos de uma série de escândalos envolvendo questões relacionadas à corrupção, geralmente ocasionada pela confusão entre interesses públicos e privados, em que estes tendem a prevalecer excessivamente sobre aqueles. Esse fato constitui um abalo aos postulados básicos que nortearam o surgimento da forma de governo republicana.

Jefferson ficou famoso pelos US \$90 mil que os promotores disseram que era proveniente de suborno, encontrados pelo FBI, em seu freezer (MARKON, 2009). 
Uma inquietude toma conta do país, levando indivíduos sem pretensões políticopartidárias as ruas em prol do respeito à coisa pública. É notória a eclosão de uma forte demanda social em repúdio à corrupção.

Observa-se que o problema debatido tem como pilar a relação entre o interesse público e privado. Diante das tensões entre ambos, a doutrina contemporânea tem impugnado o modelo tradicional da supremacia do interesse público desde que este assumiu perspectiva especial e relevante com o advento da Constituição de 1988, vez que consagrou a administração proba como um direito fundamental do cidadão.

Ressalta-se que não se pretendeu reviver o clássico paradigma da supremacia do interesse público. Entrementes, não se pode simplesmente relegá-lo a um plano inferior com o argumento de se opor a outros direitos individuais, alterando, em algumas situações, o entendimento outrora firmado sob a alegação de resguardar direitos individuais. De igual modo, é desarrazoado.

Atualmente, muito se debate sobre a inexistência da preponderância do interesse público sobre o privado. Entretanto, falta o mesmo fulgor para a análise das consequências a médio e a longo prazo do sacrifício do interesse público quando levado aos excessos. Caso essa tendência se mantenha, certamente o Estado não terá as mínimas condições de manter o mesmo aparato estrutural, financeiro e jurídico indispensáveis para a concretização dos direitos fundamentais de todos outros cidadãos, em um futuro não tão distante.

Esse assunto merece atenção especial principalmente em se tratando de casos em que são discutidas violações aos postulados da administração proba, visto que é frequente a adoção nos Tribunais de interpretações que desprestigiam o interesse público em prol de garantias individuais dos seus supostos violadores, servindo, na prática como instrumento de impunidade nos ilícitos de colarinho branco e congêneres.

Malgrado a crise de respeito à coisa pública que culminou em uma série de acontecimentos negativos a nível nacional, é possível a percepção de efeitos benéficos, como a criação de um ambiente favorável a transformações sociais positivas. É uma oportunidade ímpar de evolução. De conseguinte, a própria compreensão do Direito não pode se esquivar dessa nova realidade, obviamente compatibilizando com demais normas jurídicas ou mediante o recurso da ponderação quando o intérprete tiver que fazer escolhas de normas plausíveis para o caso concreto. 
O combate à corrupção não deve se limitar ao modelo convencional (quid pro quo), em que para configuração do ilícito é preciso que se prove a existência, ao menos, de um negócio explícito e específico. Deve contemplar também situações não convencionais, em que são comuns a interferência do poderio econômico e outros fatores na esfera de atuação pública.

\section{REFERÊNCIAS}

ALESSI, Renato. Instituciones de derecho administrativo. Trad. de Buenaventura Pellisé Prats. Tomo I. Barcelona: Casa Editorial Boch, 1970.

ÁVILA, Humberto Bergmann. Repensando o princípio da supremacia do interesse público sobre o particular. Revista Trimestral de Direito Público, São Paulo, n. 24, p. 159-180, 1998.

BAPTISTA, Patrícia Ferreira. Transformações do direito administrativo. Rio de Janeiro: Renovar, 2003.

BARROSO, Luís Roberto. Curso de direito constitucional contemporâneo: os conceitos fundamentais e a construção de um novo modelo. 5. ed. São Paulo: Saraiva, 2015.

BENEVIDES, Maria Victoria de Mesquita. A cidadania ativa: referendo, plabiscito e iniciativa popular. São Paulo: Ática, 1991.

BOLESINA, Iuri; LEAL, Mônia Clarissa Hennig. O mínimo existencial e o controle jurisdicional de políticas pública: análise de sua operacionalidade na jurisprudência do Supremo Tribunal Federal e do Superior Tribunal de Justiça. Curitiba: Multideia, 2013.

CARNEIRO JÚNIOR, Almicar Araújo. A república brasileira e o princípio constitucional anticorrupção. Tese (Doutorado em Direito, Justiça e Cidadania no século XXI)- Faculdades de Direito e Economia da Universidade de Coimbra, Coimbra, 2015.

DI PIETRO, Maria Sylvia Zanella. Direito administrativo. 28. ed. São Paulo: Atlas, 2015.

ESCOLA, Jorge Hector. El interés público como fundamento del derecho administrativo. 23. ed. Rio de Janeiro: Lumem Juris, 1989.

FIGUEIREDO, Lúcia Valle. Curso de direito administrativo. 7. ed. São Paulo: Malheiros, 2004.

GOMES, Orlando. Direitos reais. 19. ed. Atualizador por Luiz Edson Fachin. Rio de Janeiro: Forense, 2004.

MARKON, Jerry. Ex-Rep. Jefferson (D-La.) gets 13 years in freezer cash case. Washingtonpost. 2009. Disponível em: <http://www.washingtonpost.com/wpdyn/content/article/2009/11/13/AR2009111301266.html> Acessado em: 10 jan. 2017. 
MATTOS, Diogo Castor de. A seletividade penal na utilização abusiva do habeas corpus nos crimes de colarinho branco. Dissertação (Mestrado em Ciência Jurídica)-Universidade Estadual do Norte do Paraná. Jacarezinho: UENP, 2015.

MEDAUAR, Odete. Direito administrativo moderno. 17. ed. São Paulo: Revistas dos Tribunais, 2013.

MEIRELLES, Helly Lopes. Direito administrativo brasileiro. 34. ed. São Paulo: Malheiros, 2008 .

MELLO, Celso Antônio Bandeira de. Curso de direito administrativo. 29. Ed. São Paulo: Malheiros, 2015.

OSÓRIO, Fábio Medina. Existe uma supremacia do interesse público sobre o privado no direito administrativo brasileiro? Revista de Direito Administrativo, Rio de Janeiro, n. 220, p. $69-107,2000$.

POLÍCIA prende vice-presidente do facebook na América Latina em SP. G1.Globo.com. 2016. Disponível em: <http://g1.globo.com/sao-paulo/noticia/2016/03/policia-prenderepresentante-do-facebook-na-america-do-sul-em-sp.html> Acessado em: 06 jan. 2017.

PRESSE, France. Obesidade persiste em crianças e adolescentes dos Estados Unidos. G1.Globo.com. 2016. Disponível em: <http://g1.globo.com/bemestar/noticia/2016/04/obesidade-persiste-emcriancas-e-adolescentes-dos-estados-unidos.html> Acessado em: 12 jan. 2017.

SARMENTO, Daniel. Interesses públicos vs. Interesses privados na perspectiva da teoria e da filosofia constitucional. In: SARMENTO, Daniel (Org.). Interesses públicos versus interesses privados: desconstruindo o princípio da supremacia do interesse público. Rio de Janeiro: Lumen Juris, 2005, p. 23-116.

SILVA, Denise Martins Moura. Limites da supremacia do interesse público quando contrapostos ao interesse do cidadão. Dissertação. (Mestrado em Direito)- Universidade Federal de Sergipe. São Cristóvão: UFS, 2013.

SILVA NETO, Manoel Jorge e. Curso de direito constitucional. 2. ed. Rio de Janeiro: Lumen Juris, 2006.

TEACHOUT, Zephyr. Corrupcion in America: from Benjamin Franklin's snuff box to Citizens United. London: Harvard University Press, 2014.

YINGLING, M. Patrick. Conventional and unconventional corruption. Duquesne: Copyright Duquesne University, 2013. 